ARTICLE

\title{
Raw biomass electroreforming coupled to green hydrogen generation
}

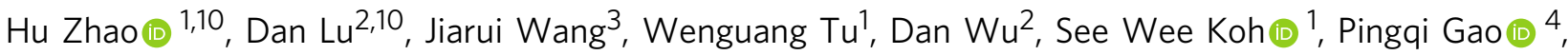

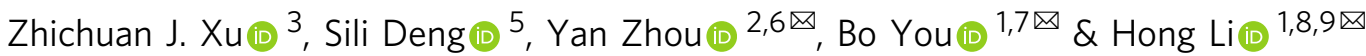

Despite the tremendous progress of coupling organic electrooxidation with hydrogen generation in a hybrid electrolysis, electroreforming of raw biomass coupled to green hydrogen generation has not been reported yet due to the rigid polymeric structures of raw biomass. Herein, we electrooxidize the most abundant natural amino biopolymer chitin to acetate with over $90 \%$ yield in hybrid electrolysis. The overall energy consumption of electrolysis can be reduced by $15 \%$ due to the thermodynamically and kinetically more favorable chitin oxidation over water oxidation. In obvious contrast to small organics as the anodic reactant, the abundance of chitin endows the new oxidation reaction excellent scalability. A solar-driven electroreforming of chitin and chitin-containing shrimp shell waste is coupled to safe green hydrogen production thanks to the liquid anodic product and suppression of oxygen evolution. Our work thus demonstrates a scalable and safe process for resource upcycling and green hydrogen production for a sustainable energy future.

\footnotetext{
${ }^{1}$ School of Mechanical and Aerospace Engineering, Nanyang Technological University, Singapore, Singapore. ${ }^{2}$ Advanced Environmental Biotechnology Centre, Nanyang Environment and Water Research Institute, Nanyang Technological University, Singapore, Singapore. ${ }^{3}$ School of Materials Science and Engineering, Nanyang Technological University, Singapore, Singapore. ${ }^{4}$ School of Materials, Sun Yat-sen University, Guangzhou, China. ${ }^{5}$ Department of Mechanical Engineering, Massachusetts Institute of Technology, Cambridge, MA, USA. ${ }^{6}$ School of Civil and Environmental Engineering, Nanyang Technological University, Singapore, Singapore. ${ }^{7}$ School of Chemistry and Chemical Engineering, Huazhong University of Science and Technology, Wuhan, Hubei, China. ${ }^{8}$ Centre for Micro-/Nano-electronics (NOVITAS), School of Electrical and Electronic Engineering, Nanyang Technological University, Singapore, Singapore. ${ }^{9}$ CINTRA CNRS/NTU/THALES, UMI 3288, Research Techno Plaza, Singapore, Singapore. ${ }^{10}$ These authors contributed equally: Hu Zhao, Dan Lu. ${ }_{\text {email: }}$ zhouyan@ntu.edu.sg; youbo@hust.edu.cn; ehongli@ntu.edu.sg
} 
A sustainable development for the future needs conversion and storage of renewable energy that replenishes naturally and swiftly such as solar and wind. There are many challenges to integrate intermittent and unpredictable renewable energies to existing electric grids without causing interruption ${ }^{1}$. Extensive research has thus been devoted to energy storage devices such as battery systems, which could electrify the end-user sectors such as light-duty transport industry and residential buildings ${ }^{2,3}$. However, most of heavy-duty transportation including aircrafts and ships, and energy-intensive industries are difficult to be powered by electricity ${ }^{4}$. In addition, large-scale implementation of energy storage using batteries could be hampered by the low earth abundance of key materials including lithium and cobalt ${ }^{5}$. To this end, the storage of renewable energy in chemical energy carries is attractive to complement the electrical storage devices. Hydrogen fuel has been considered as one of the most promising chemical energy carriers due to its high energy density, free of greenhouse gas and pollutants emission, etc. 6,7 . Therefore, to store renewable energy in hydrogen-hydrogen chemical bonds in hydrogen molecules could hold the key to a truly sustainable energy future. Indeed, worldwide efforts have been devoted towards energy storage in hydrogen fuel such as power to gas ${ }^{8}$, power to $\mathrm{X}^{9}$, and $\mathrm{H}_{2} @ S c a l e$ initiatives (www.energy.gov/eere/fuelcells/h2scale), where hydrogen is generated by water electrolysis driven by renewable energies.

Water electrolysis is an industrial process for renewable and scalable green hydrogen generation. Among the three main water electrolysis technologies, namely alkaline water electrolysis $(\mathrm{AWE})^{10}$, proton-exchange-membrane water electrolysis ${ }^{11}$, and solid-oxide water electrolysis ${ }^{12}$, AWE offers the most cost-effective and scalable method for renewable hydrogen generation ${ }^{13}$. Indeed, AWE contributes 2-3 million metric tons of hydrogen annually, i.e., about $4 \%$ global hydrogen production per year. The major obstacle for wider implementation of current water electrolysis technology is its much higher price $\left(>\$ 10 \mathrm{~kg}^{-1}\right)$ than the dominant methane reforming technology (about $\$ 2 \mathrm{~kg}^{-1}$ ) (https:// www.hydrogen.energy.gov/h2a_delivery.html) ${ }^{14}$. This could be mitigated by decreasing the electricity price that represents about $50 \%$ of the cost of AWE hydrogen production ${ }^{15}$. Thus, intensive effort has been devoted to the development of efficient catalysts ${ }^{16}$ or smart device architectures ${ }^{17}$ to lower electricity consumption. However, up to $90 \%$ of the electricity is consumed by the oxygen evolution reaction (OER) that couples to the hydrogen evolution reaction $(\mathrm{HER})^{18}$. This thermodynamic constrain suggests significant reduction of electricity consumption is not possible in HER-OER couple.

Naturally, one may think of driving AWE using renewable energies such as solar or wind (could produce electricity at a price $\left.<\$ 0.03 \mathrm{kWh}^{-1}\right)^{19}$. Nevertheless, the intermittent and uncontrollable solar or wind energy ${ }^{20}$ is not compatible with AWE due to partial load issue ${ }^{21}$, where serious gas crossover occurs when only partial electrolysis capacity (10-40\% typically for AWE) is utilized. A gas mixture of hydrogen and oxygen is explosive at the working condition of electrolyzers ${ }^{6}$. As a result, AWE system has to be shut down to remove leaked $\mathrm{H}_{2}$ when its concentration reaches $2 \%$ in the oxygen compartment ${ }^{22}$. In order to completely avoid this partial load issue, separating HER from OER in time and space by a recyclable redox mediator has been investigated, including silicotungstic acid ${ }^{23,24}$, nickel hydroxide ${ }^{25}$, (ferrocenylmethyl)trimethylammonium chloride ${ }^{26}$, and anthraquinone-2,7-disulfonic acid ${ }^{27}$. Alternatively, one could replace OER with other reactions (e.g., organic oxidation reactions) that are thermodynamically more favorable, and produce liquid products on anode ${ }^{28-31}$. These strategies could successfully remove partial load issues and thus allow water electrolysis to couple to renewable energies directly. However, the scalability of hydrogen production is limited because none of these reactants (recyclable redox or organic oxidation reactions) could be as abundant as water, the reactant of HER and OER. In order to address this scalability mismatch issue, it is necessary to couple HER to an anodic reaction that oxidizes abundant reactants. As the most abundant natural amino biopolymer, chitin is ubiquitously found in insect skeleton, fungi, and crustacean shells with an annual production of 100 billion tons in nature ${ }^{32,33}$. A knowledge gap for raw biomass electroreforming arises from the rigid polymeric structure of raw biomass. Albeit chitin has comparatively low solubility in water, recent progress shows that optimized mechanochemical amorphization can greatly circumvent this barrier $^{34,35}$.

In this study, we couple HER to the electrooxidation of the chitin $^{32}$ for cogeneration of hydrogen and acetate, which could be further upgraded to a more valuable single-cell protein. We find chitin oxidation reaction (COR) is more favorable than OER thermodynamically and kinetically in the AWE setup. We have achieved a nearly complete chitin conversion to acetic acid $(\mathrm{HAc})^{36}$. Such HER-COR couple offers a few apparent advantages. First, the hybrid electrolysis has excellent scalability with abundant reactants on both cathode (water) and anode (chitin), and higher efficiency can be obtained due to the more favorable reaction of COR compared to OER in traditional AWE. Second, the new redox couple completely removes the partial load issue since the by-product generated on the anode is dissolved in a liquid electrolyte, making AWE compatible with intermittent renewable energy. This feature allows membrane-free operation, making a single-compartment electrolyzer possible. Third, a much more valuable product (organic acids that can be further

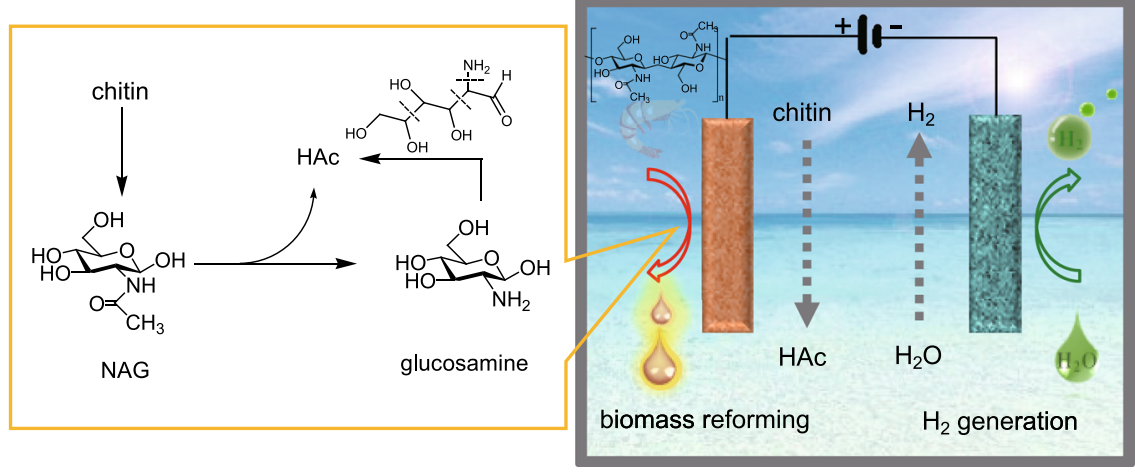

Fig. 1 Hybrid electrolysis for raw biomass reforming and hydrogen evolution. Abundant biopolymer chitin exists in exoskeleton of insects and crustaceans. Electrochemical reforming of chitin selectively to acetic acid (HAc). Left panel: possible main reaction pathways. Right panel: schematic configuration of the hybrid electrolysis. 
upgraded to protein) is produced on the anode, which can partially recover the operational cost. Since the product on the anode is almost pure acetate, no complicated separation, and extraction processes are required ${ }^{37}$. Lastly, COR offers significant environmental benefits since chitin is a major composition of solid waste $^{33,38,39}$. Therefore, the bifunctional electrolysis for largescale cogeneration of green hydrogen and commodity chemicals is highly beneficial for a sustainable future.

\section{Result and discussion}

Water electroreduction coupled with chitin electrooxidation. Figure 1 shows the schematic of the hybrid electrolysis system, where potassium hydroxide $(\mathrm{KOH})$ solution serves as the electrolyte. HER occurs on the cathode to produce hydrogen $\left(\mathrm{H}_{2} \mathrm{O}+\mathrm{e}^{-}\right.$ $\rightarrow \frac{1}{2} \mathrm{H}_{2}+\mathrm{OH}^{-}$), and $\mathrm{COR}$ proceeds on the anode to produce acetate. A membrane can be used to allow transport of $\mathrm{OH}^{-}$ions between the cathode and anode while preventing oxidation products from reaching the cathode. A reaction pathway that produces main product of interest here is illustrated in the box (left). Depolymerization of chitin produces its monomer $\mathrm{N}$ acetylglucosamine (NAG), which could be oxidized to produce HAc and glucosamine by deacetylation ${ }^{37}$. The opening of the pyranose ring in glucosamine will produce more $\mathrm{HAc}^{37}$. Since the products on the anode are soluble in the electrolyte, there is negligible gaseous product produced if COR dominates the anodic reactions. Moreover, the main product HAc is stable in the redox potential window ( -0.4 to $1.7 \mathrm{~V}$ vs. RHE), and thus will neither be further oxidized on the anode nor be reduced on the cathode. As such, a membrane-free reactor can be employed for hybrid electrolysis. In addition, the hybrid electrolysis system can directly couple to renewable energy sources since the partial load issue is removed, as will be detailed later.

Preparation of the cathode and anode. Three-dimensional hierarchical porous nickel $(h p-\mathrm{Ni})$ catalyst was prepared by a facile template-free cathodic electrodeposition of porous $\mathrm{Ni}$ microspheres onto $\mathrm{Ni}$ foam (NF) substrate, i.e., $h p$-Ni/NF (see Supplementary Fig. 1). Hydrogen bubbles evolve at cathodic potential via HER during electrodeposition, responsible for the porous structure ${ }^{30}$. The anode was obtained by activating the asprepared $h p-\mathrm{Ni} / \mathrm{NF}$ electrode at a constant current density of $50 \mathrm{~mA} \mathrm{~cm}^{-2}$ until a stable OER performance was reached. During activation, the $h p-\mathrm{Ni} / \mathrm{NF}$ electrode was used as the working electrode, and a Pt wire acted as the counter electrode. An Ag/ $\mathrm{AgCl}$ (sat. $\mathrm{KCl}$ ) electrode served as the reference electrode, which was calibrated with potassium ferricyanide prior to each usage. To fabricate the cathode, the surface of $h p$-Ni/NF electrode was converted to $\mathrm{Ni}_{2} \mathrm{P} / \mathrm{NF}$ in a chemical vapor deposition system (see Methods and Supplementary Fig. 2 for details).

Figure $2 \mathrm{a}$ depicts the scanning electron microscopy (SEM) images of the as-prepared $h p-\mathrm{Ni} / \mathrm{NF}$ sample, which shows a clear $3 \mathrm{D}$ hierarchically porous features. The starting NF support was coated with a porous electrodeposited $\mathrm{Ni}$ film decorated with porous microspheres (100-200 $\mu \mathrm{m}$ in diameter). The NF skeleton has many pores with sizes ranging from micrometers to millimeters, and the porous microspheres also have numerous pores with sizes ranging from a few to tens of micrometers. The enlarged view of the green square area in Fig. $2 \mathrm{a}$ is displayed in Fig. 2b, which shows that the electrodeposited $\mathrm{Ni}$ film is composed of loosely packed $\mathrm{Ni}$ nanoparticles separated by nanoscale pores. As a result, the $h p-\mathrm{Ni} / \mathrm{NF}$ electrode has a welldefined hierarchically porous structure with pores size ranging from nanometers to millimeters (see Supplementary Figs. 3 and 4 for more details). Such an electrode structure greatly facilitates mass transport and gas diffusion ${ }^{30}$, as well as exposes as many active sites as possible, which is responsible for the large current density observed. X-ray diffraction (XRD) pattern [the middle blue curve (as-synthesized $h p-\mathrm{Ni}$ ) in Fig. $2 c$ ] shows that the $h p$ $\mathrm{Ni} / \mathrm{NF}$ electrode contains crystalline cubic Ni (JCPDS card No. 04-0850), and this monolithic structure can endow the $h p-\mathrm{Ni} / \mathrm{NF}$ electrode with high stability and excellent electrical conductivity. Such cubic Ni phase remained after the COR test [the upper red curve (post-reaction $h p-\mathrm{Ni}$ ) in Fig. $2 c]$. The SEM images of the anode after the four-hour COR test (Fig. 2d, e) show that the integrity of the electrode structure was well retained, except for some tiny particles coating on the electrode surface, which could be the undissolved chitin crystals. The energy-dispersive X-ray spectroscopy (EDS) spectra (Fig. 2f) show that the oxygen element increases in concentration relative to that of the $\mathrm{Ni}$ element, owing to the anode activation and COR process. The elemental mappings (insets of Fig. 2f) further confirm that only nickel oxide/oxyhydroxide is present on the post-COR anode surface. Compared to that of the as-synthesized $h p-\mathrm{Ni} / \mathrm{NF}$, the peak at $852.4 \mathrm{eV}$ on $\mathrm{Ni} 2 p_{3 / 2} \mathrm{X}$-ray photoelectron spectroscopy (XPS) spectrum that is ascribed to metallic Ni almost disappeared after COR (Fig. 2g, see Supplementary Fig. 5 for the full range spectra). This indicates the completed oxidation of the electrode surface, which is consistent with the increased peak at $856.2 \mathrm{eV}$. The much stronger peak on O $1 \mathrm{~s}$ XPS spectrum of postCOR anode further confirms that the COR process caused deeper oxidation of Ni surface (Fig. 2h). The enhanced nickel oxidation is very beneficial for high COR activity because the catalytic activity centers in $\mathrm{Ni}$ anode are the high-valent nickel species ${ }^{40}$.

Electrochemical characterizations. The anode was used to oxidize chitin with $\mathrm{Ag} / \mathrm{AgCl}$ reference electrode and a $\mathrm{Pt}$ wire (or $\mathrm{Ni}_{2} \mathrm{P} / \mathrm{NF}$ electrode) as counter electrode. A certain amount of chitin was dissolved in $1.0 \mathrm{M} \mathrm{KOH}$ solution by ultrasonic treatment for $30 \mathrm{~min}$ followed by a sequential freezing-thawing process (see Methods for more details) ${ }^{41}$. The scan rate was $10 \mathrm{mV} \mathrm{s}^{-1}$ in all cyclic voltammetry $(\mathrm{CV})$ measurements. $85 \% i R$ compensation was applied to all current-voltage measurements to account for the Ohmic loss, where $R$ was obtained by electrochemical impedance spectroscopy (EIS). The $\mathrm{Ni}_{2} \mathrm{P} / \mathrm{NF}$ cathode is very active for HER in 1.0 M KOH electrolyte with a potential of $-180 \mathrm{mV}$ vs. RHE for current density of $100 \mathrm{~mA} \mathrm{~cm}^{-2}$, as displayed in the inset of Fig. 3a.

Figure $3 \mathrm{a}$ depicts the $\mathrm{CV}$ curves of the anode in $1.0 \mathrm{M} \mathrm{KOH}$ with (red) and without (black) $33.3 \mathrm{mg} \mathrm{L}^{-1}$ chitin, respectively. In the absence of chitin, the anode shows good OER activity in basic media with onset potential of $1.55 \mathrm{~V}$ vs. RHE. Significant OER current appears after $\mathrm{Ni}$ oxidation peak $\left(\mathrm{Ni}^{2+} \rightarrow \mathrm{Ni}^{3+}\right)$ at around $1.40 \mathrm{~V}$ vs. RHE, indicating $\mathrm{Ni}^{3+}$ is the active center for water oxidation $^{40}$. In the presence of chitin, the anodic current emerges earlier and increases faster than the pure OER current. Specifically, the current density is $\Delta j \sim 600 \mathrm{~mA} \mathrm{~cm}^{-2}$ (or 2.5 times) higher at $1.7 \mathrm{~V}$ vs. RHE, and the potential is $\Delta V \sim 80 \mathrm{mV}$ lower at $0.4 \mathrm{~A} \mathrm{~cm}^{-2}$, than those of the pure OER curves, suggesting COR is kinetically more favorable than OER (see labels in Fig. 3a). It is noted that, at high overpotential, nonnegligible OER could occur concurrently with COR, thus the observed current density comes from both OER and COR (OER + COR). COR and OER are believed to share the same active sites because the generated oxygen decreased when chitin was added, as demonstrated in Supplementary Fig. 6. The EIS spectra at open-circuit voltage (OCV) show that the series resistances $R_{\mathrm{s}}$ (left intersection point with $x$-axis) for both OER + COR (red circles) and pure OER (black squares) curves are similar (Supplementary Fig. 7 and the inset of Fig. 3b). In contrast, the charge-transfer resistance $R_{\mathrm{ct}}$ (diameter of the 

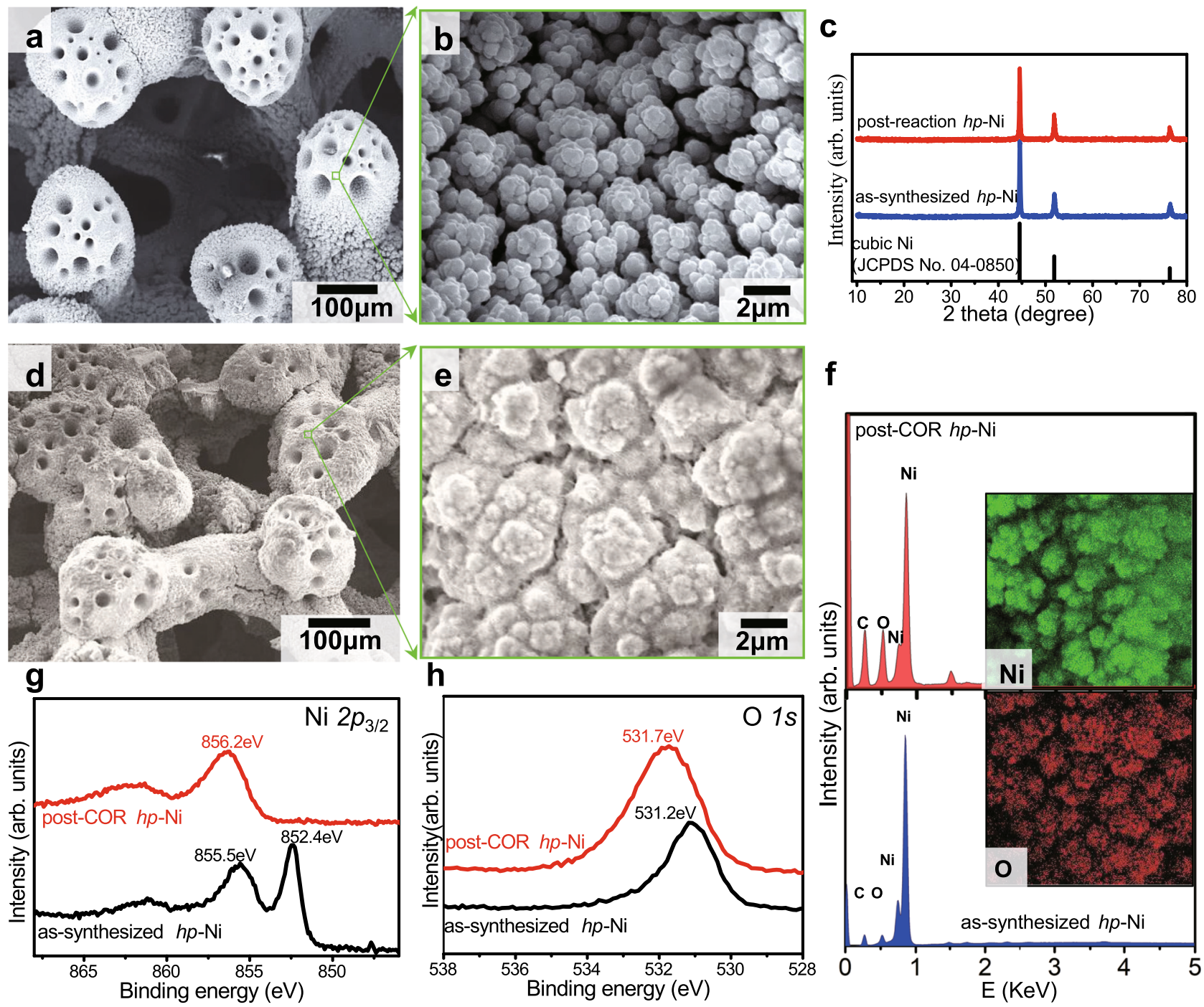

Fig. 2 Material characterization of electrode. a SEM images of an as-synthesized hp-Ni sample. b Zoom-in view of the green square in (a). c X-ray diffraction patterns of as-synthesized (blue spectrum) and post-COR samples (red spectrum) along with the standard reference of cubic Ni (black spectrum). d SEM images of a post-COR hp-Ni sample. e Zoom-in view of the green square in (d). $\mathbf{f}$ EDS spectrum of as-synthesized (blue spectrum) and post-COR sample (red spectrum). Inset: $\mathrm{Ni}$, and $\mathrm{O}$ element mapping of the post-COR sample. XPS spectrum of (g), Ni $2 p$ states, and $\mathbf{h} \mathrm{O} 1 \mathrm{~s}$ state of the samples before (black spectra) and after (red spectra) COR.

semicircle) of the OER + COR curve is 2.4 times lower than that of the pure OER curve (Supplementary Fig. 8 and Table 1). This comparison suggests that the much higher current density observed in CV scan (Fig. 3a) is caused by a much faster kinetics/reaction rate of COR than that of OER. Similar to OER, the COR current increases after the Ni oxidation peak, suggesting that high-valent $\mathrm{Ni}$ species are responsible for chitin oxidation. The differences between the current densities of OER + COR and OER at the same potential are summarized in Fig. 3b. One can see that the COR current (i.e., the difference between red and black bar) is larger than pure OER current in the full range of the potential applied, and selective chitin oxidation (negligible OER) is possible with a potential lower than $1.55 \mathrm{~V}$ vs. RHE. The generated oxygen was analyzed by gas chromatography with a thermal conductivity detector (GC-TCD), as displayed in Supplementary Fig. 9. It is confirmed that the generated oxygen is much less than the theoretical value (i.e., $\mathrm{O}_{2}: \mathrm{H}_{2}=1: 2$ ). Faradaic efficiency of $\mathrm{O}_{2}$ at $1.6 \mathrm{~V}$ vs. RHE is about $30 \%$ (Supplementary Fig. 10), consistent with the current density ratio measured in Fig. 3 b (labeled as *). The Chronoamperometry curve in Fig. $3 c$ shows that the total current (OER + COR) decreases with the reaction duration. $33.3 \mathrm{mg} \mathrm{L}^{-1}$ of the initial chitin can be mostly converted in $3.5 \mathrm{~h}$ at a potential of $1.7 \mathrm{~V}$ vs. RHE. The stability and reusability of the anode for chitin oxidation were also evaluated by repeating oxidation of fresh chitin samples using the same anode. As shown in the inset of Fig. 3c, the activity of the anode for chitin oxidation can be wellpreserved in three consecutive runs, which can also be corroborated by similar EIS cures (Supplementary Fig. 11). To significantly increase the chitin solubility in $\mathrm{KOH}$ electrolyte, we also conducted a mechanochemical pretreatment process (see Supplementary Fig. 12 and Methods for details). Oxidation of $3.5 \mathrm{~g} \mathrm{~L}^{-1}$ milled chitin (M-COR curve in Fig. 3d) shows much higher current density with an overpotential reduction of $170 \mathrm{mV}$ owing to the increased solubility (Supplementary Figs. 13 and 14), as well as the thermodynamic and kinetic favorability (see Supplementary Fig. 15), due to the greatly reduced molecular weight that will be detailed later. In order to see the potential of COR in energy saving, we tested the monomer of chitin, NAG, which can dissolve well in the electrolyte. As shown in Fig. 3d, the 
a

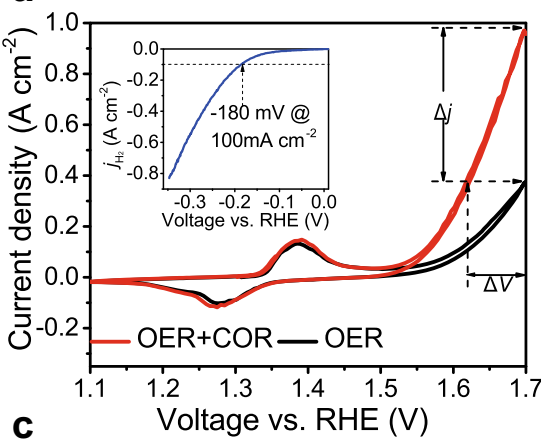

C

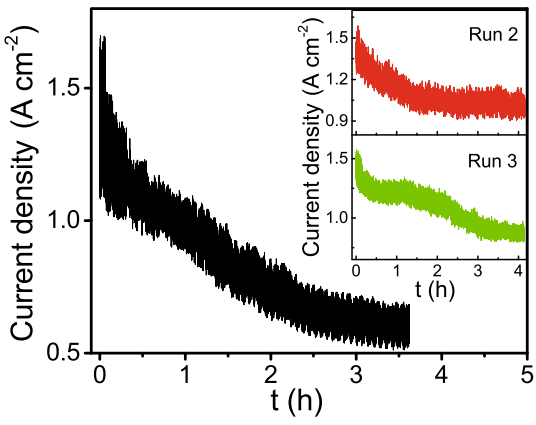

b

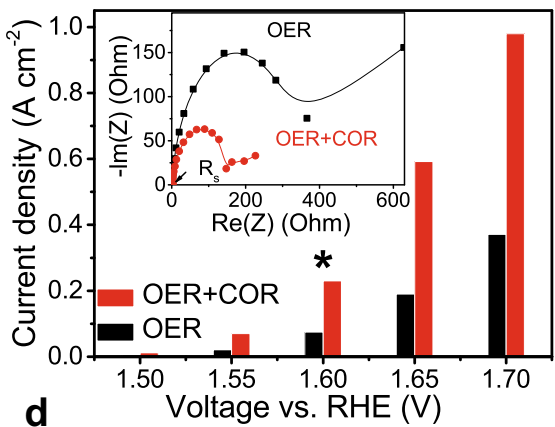

d

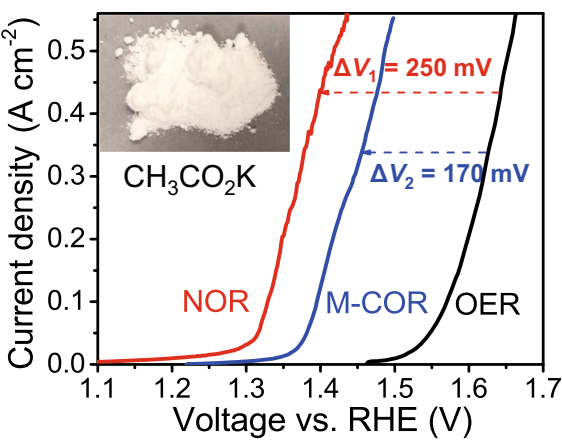

Fig. 3 Electrochemical characterization. a Cyclic voltammograms of anodic reactions at scan rate of $10 \mathrm{mV} \mathrm{s}^{-1}$ in $1.0 \mathrm{M} \mathrm{KOH}$ before (OER; black curves) and after adding $33.3 \mathrm{mg} \mathrm{L}^{-1}$ of chitin (OER + COR; red curves). $\Delta$ j labels the current density difference at $1.7 \mathrm{~V}$ vs. RHE, and $\Delta V$ labels the potential difference at $0.4 \mathrm{~A} \mathrm{~cm}^{-2}$. Inset: Linear sweep voltammograms of HER using $\mathrm{Ni}_{2} \mathrm{P} / \mathrm{NF}$ catalyst, where the potential for $100 \mathrm{~mA} \mathrm{~cm}^{-2}$ is labeled. b Comparison of current density at various potential in $1.0 \mathrm{M} \mathrm{KOH}$ solution with (red bars) and without (black bars) $33.3 \mathrm{mg} \mathrm{L}^{-1}$ chitin. Inset: the corresponding electrochemical impedance spectra (EIS) at open-circuit potential. *labels the voltage where the faradaic efficiency of oxygen evolution is characterized in Supplementary Fig. 10. c Consecutive three runs (black, red, and green curves represent the first, second, and third run, respectively) of chitin oxidation reaction (COR) in $1.0 \mathrm{M} \mathrm{KOH}$ with $33.3 \mathrm{mg} \mathrm{L}^{-1}$ chitin at a constant potential of $1.7 \mathrm{~V}$ vs. RHE. Inset: chronoamperometry curves of the second (upper) and third (lower) run. $\mathbf{d}$ Linear sweep voltammograms of anodic reactions at $5 \mathrm{mV} \mathrm{s}^{-1}$ in $1.0 \mathrm{M} \mathrm{KOH}$ (OER; black curve) and at the condition of containing $2.2 \mathrm{~g} \mathrm{~L}^{-1} \mathrm{~N}$-acetyl glucosamine (red curve labeled with NOR) and $3.5 \mathrm{~g} \mathrm{~L}^{-1}$ milled chitin (blue curve labeled with M-COR). Arrow indicates the shift of potential after adding the corresponding biomass. Inset: a picture of $436 \mathrm{mg}$ of oxidation product potassium acetate $\left(\mathrm{CH}_{3} \mathrm{CO}_{2} \mathrm{~K}\right)$.

NAG oxidation reaction (NOR) current with $2.2 \mathrm{~g} \mathrm{~L}^{-1}$ of NAG as reactant leaps at around $1.24 \mathrm{~V}$ vs. RHE, which is much lower than the onset potential of OER around $1.49 \mathrm{~V}$ vs. RHE. As a result, highly selective NAG oxidation (without OER) occurs in the potential window ranging from 1.24 to $1.49 \mathrm{~V}$ vs. RHE. Such a low onset potential of NOR indicates that $\mathrm{Ni}^{2+}$ is able to oxidize NAG. The $250 \mathrm{mV}$ reduction in OER overpotential corresponds to $15 \%$ energy saving in electrolysis. It is worth noting there is negligible oxygen detected by GC-TCD up to $1.45 \mathrm{~V}$ vs. RHE (Supplementary Fig. 16). Furthermore, a previously reported precipitation method was adopted to extract potassium acetate product (see Supplementary Fig. 17 and Methods for details). An optical image of the powder of potassium acetate hydrate $\left(\mathrm{CH}_{3} \mathrm{CO}_{2} \mathrm{~K} \cdot \mathrm{xH}_{2} \mathrm{O}\right)$ product is inserted in Fig. $3 \mathrm{~d}$, with the detailed characterizations shown in Supplementary Figs. 18-20. It is noted that the energy $\Delta \mathrm{G}$ needed for pyranose-ring opening and glycosidic bond breaking is much lower than that of water splitting ${ }^{42-44}$. This is consistent with the observed much lower onset potential of NOR than that of OER. However, the thermodynamic advantage of COR over OER is much smaller due to the high degree of polymerization of NAG in chitin, resulting in the extra energy barrier arising from depolymerization.

COR product identification and quantification. The oxidation products on anode were first identified by GC-mass spectrometry (GC-MS) method after liquid-liquid extraction (LLE) and solid-phase extraction (SPE) using acetyl acetate (EAc) and dichloromethane (DCM) as the solvent and SPE cartridge as the solid-phase column, respectively (see Methods for details). In order to test all possible COR products/ intermediates, we collected the products at various stages of reaction before the reactant was fully converted. LLE extraction using EAc solvent (red spectrum in Fig. 4a) shows volatile fatty acid (VFA) products, which contains dominantly HAc with minor formic acid, in obvious contrast to flat background spectrum (solvent only). SPE extraction result (Fig. $4 \mathrm{~b}$ ) shows $\mathrm{N}$-containing chemicals, where NMP appears to be the dominant one. Various other intermediate products were also found by other extraction methods, as shown in Supplementary Fig. 21. To quantify the yield of HAc, GC with flame-ionization detector (GC-FID) measurement was performed, as shown in Fig. 4c. The spectrum of COR product after completely converting $133.3 \mathrm{mg} \mathrm{L}^{-1}$ of chitin, along with that of the control sample consists of $0.1 \mathrm{mM}$ of standard VFAs, indicates a HAc concentration of $0.5 \mathrm{mM}$. In order to find out the solubility of chitin in our electrolyte, total carbon content (TOC) was measured and then plotted against added carbon (by weighing chitin reactant), as depicted in Supplementary Fig. 13. One can see that our freeze-thaw method (see Methods) is able to achieve chitin solubility of $>=8.3 \mathrm{mg} \mathrm{L}^{-1}$ in $1.0 \mathrm{M} \mathrm{KOH}$ solution. HAc yield from COR was then calculated by the ratio of carbon in HAc product to that in the chitin reactant. As shown in Fig. $4 \mathrm{~d}$ and Supplementary Fig. 22, the completely dissolved chitin could be effectively oxidized to HAc with over $90 \%$ yield, corroborating the opening of pyranose rings in chitin. The polymeric nature of the freeze-thawing dissolved chitin was further confirmed by matrix-assisted laser desorption/ionization-time of flight-mass spectrometry (MALDI-TOF-MS) (inset of Fig. 4d) and ${ }^{1} \mathrm{H}$ 
a

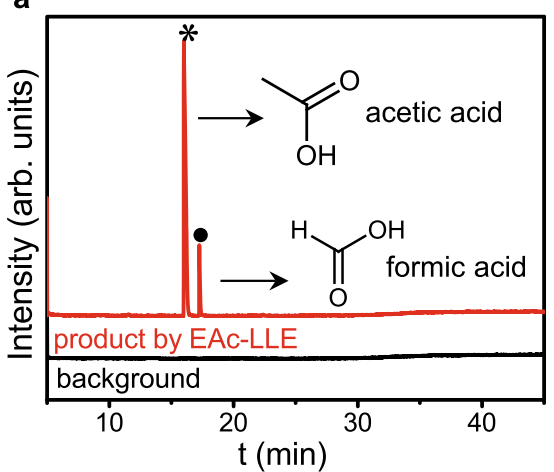

c

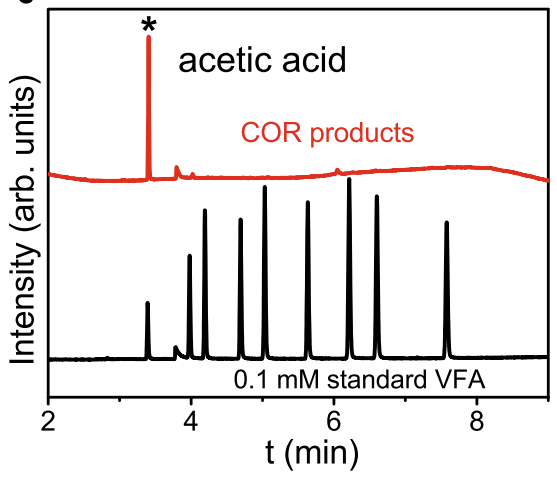

b

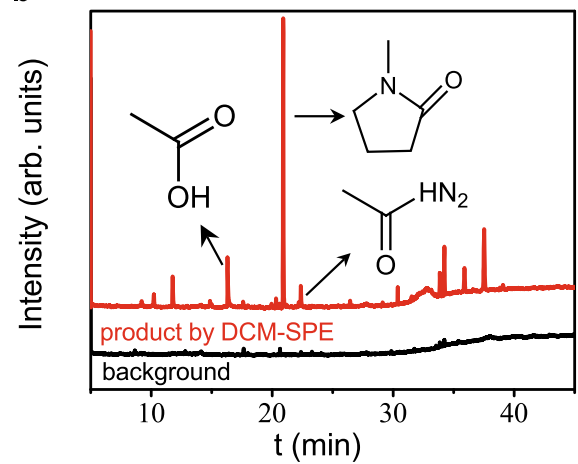

d

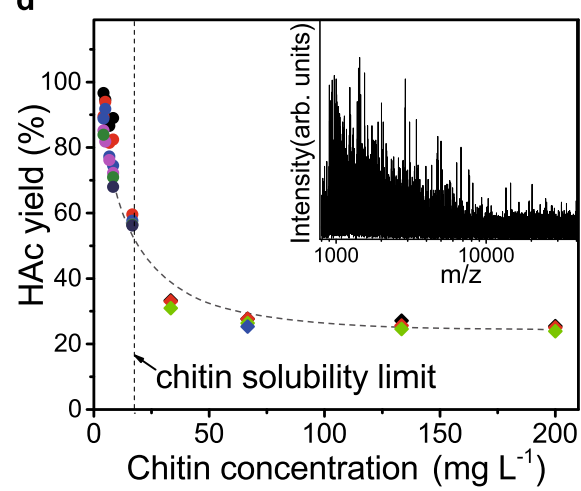

Fig. 4 Identification and quantification of products. Gas chromatography-mass spectrum (GC-MS) analysis of anodic reaction products after $\mathbf{a}$, liquid-liquid extraction (LLE) and $\mathbf{b}$ solid-phase extraction (SPE). The black curves in (a) and (b) are spectra of background. The corresponding chemicals associated with the main peaks are labeled. c GC-FID quantification of acetic acid. The spectrum of the standard VFAs sample (black spectrum) is shown for comparison. $\mathbf{d}$ Yield curve of acetic acid. The vertical dotted line labels the chitin solubility limit using freeze-thawing pretreatment. Inset: MALDI-TOF mass spectra of freeze-thawing dissolved chitin in $1.0 \mathrm{M} \mathrm{KOH}$ solution. Each data point represents an individual sample.

nuclear magnetic resonance (NMR) spectra (Supplementary Fig. 23). The possible reaction pathways are illustrated in Supplementary Fig. 24 based on the intermediates and products identified. First, chitin is depolymerized and deacetylated under anodic condition to afford glucosamine, releasing HAc from the side chain. Afterward, most glucosamine is further hydrolyzed to open the ring, followed by several oxidations and bond-breakings. All intermediates are unstable under the oxidative environment and finally converted into small organic acids as the reaction progresses. Due to the highly oxidative reaction conditions, only HAc and minor formic acid were collected eventually. On the other hand, minor glucosamine undergoes dehydration to form furanic compounds, followed by either oxygen-nitrogen exchange to produce $\mathrm{N}$-methyl-2-pyrolidone, or rupture of amine group to afford tetrahydrofurfuryl alcohol that have all been detected.

Single-compartment hybrid electrolyzer driven by solar energy. We accessed the feasibility of safe hydrogen production driven by intermittent solar energy via PV panels on the roof of our laboratory (N $1^{\circ} 20^{\prime} 54.4^{\prime \prime}$; E $103^{\circ} 40^{\prime} 59.3^{\prime \prime}$; $2-5$ pm on 14 June 2019 ; partially cloudy). Commercial PV panels (maximum output power $50 \mathrm{~W}$ each) were employed to power a sealed single-compartment reaction cell (see Supplementary Fig. 25 and Movie 1 for the detailed setup), where the generated gaseous products were collected by using a few gas sampling bags $(1 \mathrm{~L}$ each). Supplementary Fig. 26a shows the filling of sampling bags by gaseous products at four different reaction times $(0,12.5,24,51.3 \mathrm{~min})$ with milled chitin as the reactant (see the inset of Supplementary Fig. 26b for the homemade sealed reactor). The oxygen concentrations of the gaseous products in the 4 sampling bags collected sequentially are depicted in Supplementary Fig. 26b, and the corresponding faradaic efficiencies of COR and OER at different reaction time are shown in Supplementary Fig. 27. One can see that the oxygen concentration of the gas products remains below the exposure limit of hydrogen-oxygen mixture $\left(6 \% \mathrm{O}_{2}\right.$ in $\mathrm{H}_{2}-\mathrm{O}_{2}$ mixture as indicated by the dashed line) for the first 3 sampling bags despite the fluctuating output power from the PV panels (between 28.5 and $54 \mathrm{~W}$ ) due to the presence of moving clouds. The recorded PV output voltage (from voltmeter) varied between 3.0 and $3.6 \mathrm{~V}$, and the $i R$-corrected voltage range was $2-2.1 \mathrm{~V}$ (see Supplementary Table 2). It's worth noting that more oxygen evolved when the reactant concentration decreased in the electrolyte as the reaction progressed. Supplementary Fig. 26c shows the current density response when fresh reactants $(5 \mathrm{~mL}$ every time) were added four times sequentially to the reactor $(25 \mathrm{~mL}$ milled chitin with a concentration of $3.5 \mathrm{~g} \mathrm{~L}^{-1}$ ). One can see an apparent current leap upon the addition of fresh reactant, suggesting $\mathrm{M}$-COR dominated the reactions. When the reactant concentration remained high, the $\mathrm{O}_{2}$ concentration in the gaseous product remained low. Therefore, a fluidic cell with constantly added reactants should be employed to further minimize OER. Supplementary Fig. 26d shows the $\mathrm{H}_{2}$ gas production rate derived from the collected $\mathrm{H}_{2}$ gas, which reaches $0.073 \mathrm{~L} \mathrm{~min}^{-1}$ (electrode area of $28 \mathrm{~cm}^{2}$ ). It is noted that the catalyst remained active after repeated cycles of reaction (Fig. $3 \mathrm{c}$ and the inset) and prolonged reaction time (Supplementary Fig. 28), suggesting the anode is stable for both COR and OER. From the evolution of the reactant color with increased reaction time (Supplementary Fig. 29), one can see that the electrolyte rapidly became clearer in the first 3-h reaction, and then color slowly faded. Eventually, the electrolyte became almost clear after 24-h reaction. The final product consisted of mainly HAc with minor formic acid $(<5 \%)$ as suggested by GC-MS (Supplementary Fig. 30), GC-FID (inset of Supplementary Fig. 26d), and high-performance liquid 
chromatography (HPLC) measurements (see Methods for details). The yield of HAc was obtained to range from 73.7 to $77.5 \%$ from batch to batch.

Our proof-of-concept single-compartment AWE prototype shows great compatibility with intermittent solar energy. With decreasing the price of PV and wind electricity to $\$ 0.02 \mathrm{~kW} \mathrm{~h}^{-1}$, conventional AWE can be more cost-effective ( $\left.\$ 100-400 \mathrm{~kW}^{-1}\right)$ than methane reforming ${ }^{15}$. Our hybrid electrolysis will further reduce the price of green hydrogen production via water electrolysis. Moreover, direct coupling of renewable energy to electrolyzer avoids the integration of renewable energy to electrical grid, which faces many challenges currently ${ }^{1}$. This will also reduce electricity consumption in various AC/DC converters, voltage/current regulators, etc. Lastly, the single-compartment electrolyzer simplifies the overall device and system design, and thus reduces the cost of manufacturing, maintenance, and operation. Albeit the energy consumption of ball mill at current stage still hinders the practical application of our hybrid electrolysis to some extent, further reduction of energy consumption by using the appropriate cocatalyst or/and increasing the processing scale (see Supplementary Notes, Figs. 31 and 32, and Tables 4-7 for more details). Therefore, such a hybrid AWE will facilitate the wide implementation of water electrolysis by potentially reduced cost and increased safety, highly beneficial for a sustainable energy future.

Electrochemical conversion of crude shrimp shells. To further extend the sustainability of our hybrid electrolysis, crude shrimp shell (as a replacement for chitin) from seafood waste was fed to the electrolyzer. Shrimp shells (Caridina heteropoda), which contain $29 \mathrm{wt} \%$ calcium carbonate $\left(\mathrm{CaCO}_{3}\right)$, were pretreated under the same kaolinite-assisted ball milling process as chitin pretreatment, except that different ratio was used. $\mathrm{CaCO}_{3}$ remained insoluble after ball milling and was removed by a simple filtration after dispersing the products in water. While the rest $\sim 71 \mathrm{wt} \%$ mass (mainly protein and chitin) underwent partial depolymerization and amorphization under the mechanochemical treatment and then dissolved in water. The MALDITOF-MS result (Fig. 5a) shows that the molecular weight of the dissolved section mainly locates in the range of $800-1300 \mathrm{Da}$, while the results from size exclusion chromatography coupled with organic carbon detection and organic nitrogen detection (SEC-OCD-OND) (see the inset of Fig. 5a) demonstrate that the main categories of the dissolved section are humic substance and low molecular weight polysaccharide. Oxidation of $6.0 \mathrm{~g} \mathrm{~L}^{-1}$ milled shrimp shell (M-SOR curve in Fig. 5b) shows similar current density increase as M-COR, and even lower onset potential. GC-MS characterizations (Fig. 5c) show that the main product is still HAc with trivial formic acid. And the GC-FID (Fig. 5d) quantification shows that the yield of acetic acid reached up to 42 toc\%. It is worth noting that our electrolyzer shows significantly higher current density than the reported electrochemical conversion of lignocellulose ${ }^{45-64}$, suggesting a big step towards practical use (see detailed comparison in Supplementary Table S3).

In this work, we employed COR to replace OER in traditional AWE. Electrocatalytic oxidation of chitin that produces highpurity organic acids is coupled to water reduction. Such modified electrolysis is much safer than traditional water electrolysis because the product acetate is dissolved in the electrolyte, and thus avoids the formation of the explosive gas mixture with hydrogen. This feature allows direct coupling of intermittent solar energy to water electrolysis because the partial load issue is addressed. A solar energy-driven membrane-free singlecompartment reactor is demonstrated to produce hydrogen gas at the rate of $73 \mathrm{~mL}$ per min with over $70 \%$ yield of acetic acid from chitin. Most importantly, chitin oxidation is as scalable as water reduction for hydrogen generation because chitin is produced more than 100 billion tons annually in nature. Chitin-containing waste shrimp shell also shows a high conversion rate, suggesting the excellent sustainability of the process. Putting together, the new hybrid electrolysis system has a few advantages over the traditional water electrolysis including (1) free of partial load issue and thus compatible with intermittent renewable energy sources, (2) electrooxidation of chitin reforms raw biomass to commodity chemicals in a green process, (3) much safer operation due to highly soluble products generated on anode, (4) much lower cost due to cheap renewable electricity, simple device configuration, and easy operation, (5) much more valuable product (organic acid) than oxygen is produced on anode, and (6) significant environmental benefit by upcycling chitin/shrimp shell waste, a major composition of solid waste. Therefore, our work paves the way towards a safe and scalable raw biomass electroreforming and green hydrogen production for a sustainable future.

\section{Methods}

Chemicals. Ammonium chloride, nickel sulfate hexahydrate, potassium hydroxide, potassium ferricyanide, formic acid, sodium sulfate, dichloromethane, ethyl acetate, kaolinite, and chitin were purchased from Sigma-Aldrich, hydrochloric acid and methanol were purchased from VWR, Sodium hypophosphite monohydrate was purchased from Alfa Aesar, $\mathrm{Ag} / \mathrm{AgCl}$ (sat $\mathrm{KCl}$ ) was purchased from $\mathrm{CHI}$, and other chemicals were purchased from commercial vendors. All chemicals were used as received without further purification. Deionized water $(18 \mathrm{M} \Omega \mathrm{cm})$ was used in all experiments.

Synthesis of $\boldsymbol{h p}$-Ni/NF. $h p-\mathrm{Ni} / \mathrm{NF}$ anode was prepared by a facile template-free cathodic electrodeposition of porous $\mathrm{Ni}$ microsphere arrays on a pre-shaped $\mathrm{Ni}$ foam $\left(0.5 \times 0.5 \mathrm{~cm}^{2}\right)$. Typically, the deposition was performed in a standard twoelectrode configuration at room temperature with an electrolyte of $2.0 \mathrm{M} \mathrm{NH}_{4} \mathrm{Cl}$ and $0.1 \mathrm{M} \mathrm{NiSO}_{4}$. Pre-shaped commercial $\mathrm{Ni}$ foam and platinum wire were used as the working electrode and counter electrode, respectively. The electrodeposition was carried out at a constant current of $-2 \mathrm{~A} \mathrm{~cm}^{-2}$ for $500 \mathrm{~s}$ to obtain $h p-\mathrm{Ni} / \mathrm{NF}$ samples.

Synthesis of $\mathbf{N i}_{\mathbf{2}} \mathbf{P} / \mathbf{N F}$. $\mathrm{Ni}_{2} \mathrm{P} / \mathrm{NF}$ was synthesized by phosphorization of the as synthesized $h p-\mathrm{Ni} / \mathrm{NF}$ according to the literature with minor modification ${ }^{65}$. Specifically, the $h p-\mathrm{Ni} / \mathrm{NF}$ was placed at the center of a tube furnace, with $1.0 \mathrm{~g}$ of $\mathrm{NaH}_{2} \mathrm{PO}_{2} \cdot \mathrm{H}_{2} \mathrm{O}$ at the upstream near $h p-\mathrm{Ni} / \mathrm{NF}$. After flush with argon, the furnace was quickly heated up to $400{ }^{\circ} \mathrm{C}$ at a ramping rate of $10^{\circ} \mathrm{C} \mathrm{min}-1$ and kept at $400{ }^{\circ} \mathrm{C}$ for $2 \mathrm{~h}$. Then, the temperature of the furnace was naturally cooled down to room temperature.

Pretreatment of chitin. The kaolinite-assisted milling experiments were conducted on ball mill Emax (Retsch) with two $125 \mathrm{~mL}$ zirconium oxide grinding jars and $0.5 \mathrm{~mm}$ size zirconium oxide grinding balls. In order to maximize the solubility of milled chitin samples, the milling conditions (packing degree, milling speed, and the ratio of chitin and kaolinite) were optimized. Similar to the former result, higher milling speed and packing degree resulted higher solubility ${ }^{35}$. Specifically, $3.0 \mathrm{~g}$ chitin and $6.0 \mathrm{~g}$ kaolinite were loaded into each grinding jar with $70 \%$ packing degree of grinding balls, and milled under $2000 \mathrm{rpm}$ for $6 \mathrm{~h}$. The temperature of the grinding jar was controlled by the machine built-in temperature controller not to exceed $65^{\circ} \mathrm{C}$ during the whole milling process. The milled chitin samples were washed with a specific volume of DI water and centrifuged to recycle kaolinite. The precipitated kaolinite could be reused, while the dissolved chitin was collected as a reactant of hybrid electrolysis.

Pretreatment of raw shrimp shell. A similar ball-mill procedure was applied to crude shrimp shell waste. The crude shrimp shells used were glass shrimps (Caridina heteropoda) shells ${ }^{34}$ bought from a local supermarket, which were peeled off (no flesh residue) directly from shrimps, followed by air dried and ground to powders with a blender. Prior to ball-mill decomposition, similar quantification method was employed to confirm the similar content of chitin, $\mathrm{CaCO}_{3}$, and protein as that in the previous reports ${ }^{34}$. The kaolinite-assisted milling experiments were the same as the pretreatment of chitin, except $6.0 \mathrm{~g}$ crude shrimp shell and $6.0 \mathrm{~g}$ kaolinite were used as the feed in each jar. 
a
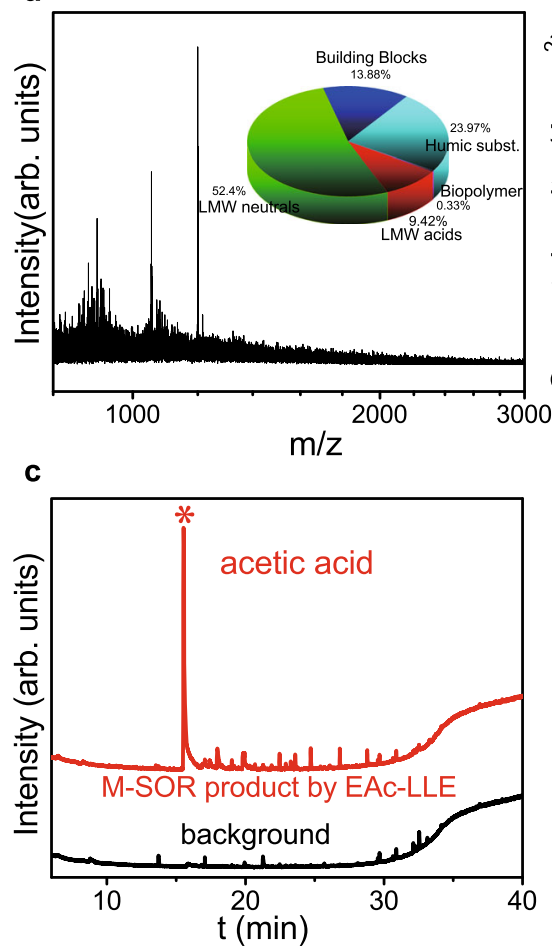

b
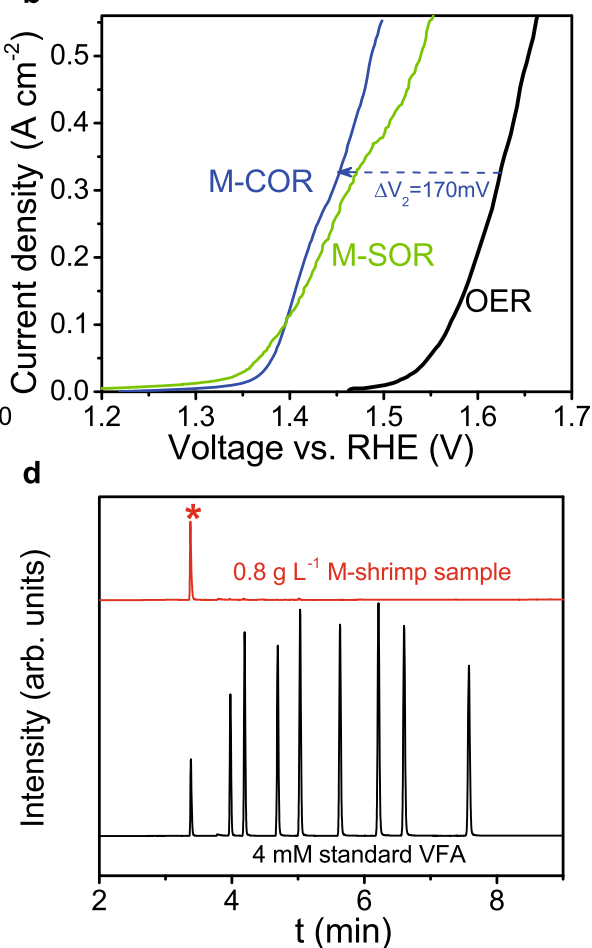

Fig. 5 Electrochemical conversion of $\mathbf{M}$-shrimp shell. a MALDI-ToF mass spectra of soluble products from ball-milled crude shrimp shell. Inset: soluble substances fractionation of ball-milled shrimp shell. b LSV of anodic reactions at $5 \mathrm{mV} \mathrm{s}^{-1}$ in $1.0 \mathrm{M} \mathrm{KOH}$ with $6.0 \mathrm{~g} \mathrm{~L}^{-1}$ milled shrimp shell (green curve labeled with M-SOR). The anodic OER (black curve) and M-chitin oxidation reaction (blue curve labeled with M-COR) curves are also plotted for comparison. c GC-MS identification of anodic oxidation product of ball-milled shrimp shell. The black spectrum represents the background. $\mathbf{d}$ GC-FID quantification of acetic acid. The spectrum of standard VFAs sample (black spectrum) is shown for comparison.

Material characterizations. SEM and element mapping were conducted on an FESEM 7600F. X-ray diffraction patterns were recorded on a Shimadzu XRD-6000. The X-ray photoelectron spectroscopy analyses were performed using a Kratos Axis Supra Spectrophotometer. X-ray photoelectron spectra were collected using the monochromatic $\mathrm{Al} \mathrm{Ka}$ source $(1486.7 \mathrm{eV})$ at a $300 \times 700 \mu \mathrm{m}^{2}$ spot size. Lowresolution survey and high-resolution region scans at the binding energy of interest were collected for each sample. To minimize charging, all samples were flooded with low-energy electrons and ions from the instrument's built-in charge neutralizer. The samples were also sputter cleaned inside the analysis chamber with $1 \mathrm{keV} \mathrm{Ar}+$ ions for 30 seconds to remove adventitious contaminants and surface oxides. All XPS data were fitted using Shirley background together with GaussianLorentzian function using CASA XPS software, and energy corrections were calibrated by referencing the $\mathrm{C} 1 s$ peak of adventitious carbon to $284.8 \mathrm{eV}$.

Electrochemical measurements. $1.0 \mathrm{M} \mathrm{KOH}$ solution was chosen as the basic electrolyte, and different types of chitin-related biomass were added to study the corresponding oxidation process. First, a certain amount of chitin was dissolved in $1.0 \mathrm{M} \mathrm{KOH}$ solution by 0.5 -h ultrasonic treatment and the sequential freezing process from room temperature to $-20^{\circ} \mathrm{C}$. Before the electrooxidation process, the chitin solution was defrosted at room temperature. Ball milling pretreatment of chitin and raw shrimp shells were also adopted to replace freeze-thawing process. The electrooxidation process was performed on a Bio-logic vsp-300 electrochemical workstation with a three-electrode glass cell configuration at room temperature. The $h p-\mathrm{Ni} / \mathrm{NF}$ was used as the working electrode, $\mathrm{Pt}$ wire or $\mathrm{Ni}_{2} \mathrm{P} / \mathrm{NF}$ acted as the counter electrode, and $\mathrm{Ag} / \mathrm{AgCl}$ (sat. $\mathrm{KCl}$ ) electrode was employed as the reference electrode. The reference electrode was calibrated with potassium ferricyanide prior to each usage. All newly synthesized anode catalysts were activated at a constant current density of $50 \mathrm{~mA} \mathrm{~cm}^{-2}$ until a stable OER performance was obtained. After the electrochemical activation process, the $h p-\mathrm{Ni} / \mathrm{NF}$ electrode was used as the anode to electrooxidize chitin or chitin-containing shrimp shell waste. Ten cycles of cyclic voltammetry (CV) scan was performed before each chronopotentiometry transformation of chitin. All scan rates were set at $10 \mathrm{mV} \mathrm{s}^{-1}$ unless specified. All the potentials reported were converted from vs. $\mathrm{Ag} / \mathrm{AgCl}$ to vs. RHE (reversible hydrogen electrode) by adding a value of $0.197+0.059 * \mathrm{pH}$. The $85 \%$ iR compensation was applied with R obtained from EIS measurement to account for the parasitic Ohmic loss.

Purification of synthesized acetate and cycling of the system. A similar purification method as previous report ${ }^{66}$ was used with minor modification. Liquid post-reaction solution was concentrated at $40^{\circ} \mathrm{C}$ under vacuum to viscous state. This concentrated product was further cooled to $0^{\circ} \mathrm{C}$ in an ice bath. A fleck of potassium acetate was added to initialize crystallization. The product was allowed to crystallize at $0{ }^{\circ} \mathrm{C}$ for $30 \mathrm{~min}$. The crystalline slurry was then filtered over a medium-porosity glass frit and compacted to aid the removal of any excess $\mathrm{KOH}$ solution from the crystalline product. The resulting solid was further dried at $80^{\circ} \mathrm{C}$ under vacuum condition for one day to get acetate hydrate product with purity of $99 \%$. The remaining $\mathrm{KOH}$ solution can be further recycled for the next run of electrolysis, as depicted in Supplementary Fig. 33.

'H NMR and MALDI-TOF-MS analysis. MALDI-TOF-MS mass spectra were obtained using a Bruker Autoflex III Smartbeam TOF/TOF 200 system equipped with a nitrogen laser $(337 \mathrm{~nm}, 200 \mathrm{~Hz}$ maximum firing rate) with a mass range of $<400,000 \mathrm{Da}$. The sample was prepared by mixing $1 \mu \mathrm{L}$ product solution with $1 \mu \mathrm{L}$ saturated 2,5-dihydroxybenzoic acid (2,5-DHB) matrix solution. ${ }^{1} \mathrm{H}$ NMR spectra were recorded on Bruker AVANCE spectrometers operating at $500 \mathrm{MHz}$ at room temperature. Prior to MALDI-TOF-MS and NMR testing, the freeze-thawing dissolved chitin sample was filtered through $4.5 \mu \mathrm{m}$ membrane. In order to obtain qualitative molecular weight information of freeze-thawing dissolved chitin, commercial chitosan dissolved in diluted $\mathrm{HCl}$ solution and $\mathrm{N}$-acetyl glucosamine in DI water was used as reference under the same testing condition. For the NMR quantification of the collected crystal solid, a certain concentration of collected solid in deuterated water was prepared and maleic acid was used as internal standard. And the purity of acetate was calculated by the ratio of the tested concentration of acetate to the prepared concentration of acetate.

Quantification of gaseous product. All reactions were performed in a singlecompartment electrochemical cell with $h p-\mathrm{Ni} / \mathrm{NF}$, Pt wire, and $\mathrm{Ag} / \mathrm{AgCl}$ (sat. $\mathrm{KCl}$ ) as the working, counter, and reference electrode, respectively. Before each reaction, we purged argon for $20 \mathrm{~min}$ to remove the air in the cell. After specific reaction time or passing a specific amount of charge, $0.5 \mathrm{~mL}$ gas was injected into GC-TCD (Agilent $6890 \mathrm{~N}$, TCD detector, argon as carrier gas, $5 \AA$ molecular sieve column) for quantification. For OER + COR reactions, the electrolyte was $1.0 \mathrm{M} \mathrm{KOH}$ solution with $33.3 \mathrm{mg} \mathrm{L}^{-1}$ of chitin. The potential was held constant at $1.6 \mathrm{~V}$ vs. RHE. For NOR reaction, the electrolyte was $1.0 \mathrm{M} \mathrm{KOH}$ solution with $2.2 \mathrm{~g} \mathrm{~L}^{-1}$ of $\mathrm{NAG}$, and the potential was varied from $1.25 \mathrm{~V}$ to $1.5 \mathrm{~V}$ vs. RHE. For oxidation of milled chitin (M-COR), the electrolyte was $1.0 \mathrm{M} \mathrm{KOH}$ solution with $3.5 \mathrm{~g} \mathrm{~L}^{-1} \mathrm{M}$ chitin, and the applied potential range was $1.35-1.5 \mathrm{~V}$ vs. RHE. While for the solar 
energy-driven two-electrode cell, the electrolyte was $1.0 \mathrm{M} \mathrm{KOH}$ solution with $5.0 \mathrm{~g} \mathrm{~L}^{-1}$ dissolved M-chitin.

Biomass oxidation product identification. The identification of products and intermediates were performed on GC-MS (gas chromatography-mass spectrometry, GCMS-QP2010ULTRA, Shimadzu) with ZB- WAXplus (Phenomenex) column of $30 \mathrm{~m} \times 0.25 \mathrm{~mm}$ with a film thickness of $0.25 \mu \mathrm{m}$. For the intermediate's identification, the reaction solutions at different reaction time, ranging from $10 \mathrm{~min}$ to $2 \mathrm{~h}$, were collected. For product identification, 4 runs of reaction solution were collected for further extraction. Prior to extraction, the reaction solutions were acidified with $37 \mathrm{wt}$ $\% \mathrm{HCl}$ solution to $\mathrm{pH}$ value of 2.0. The Acidified solutions were further liquid-liquid extracted using dichloromethane (DCM) and ethyl acetate and solid-liquid extracted with cartridges (Waters Oasis ${ }^{\circledR}$ HLB, Waters Corporation, United States), respectively. Three microliters of extracted samples were injected for each test. The splitless injection was used at $240^{\circ} \mathrm{C}$ with helium as a carrier gas at $1 \mathrm{~mL} \mathrm{~min}^{-1}$. The temperature program was as follows: $50^{\circ} \mathrm{C}$, hold $7 \mathrm{~min}$, increase $7^{\circ} \mathrm{C} \mathrm{min}-1$ to $240^{\circ} \mathrm{C}$, hold for $14 \mathrm{~min}$. The MS was operated in electron ionization (EI) mode with the ion source temperature at $220^{\circ} \mathrm{C}$, and mass spectra were acquired from $\mathrm{m} / \mathrm{z} 30$ to 500 after a 5-min solvent cut time. The peaks were identified using the NIST11 library (National Institute of Standards and Technology, Gaithersburg, MD, http://www.nist. gov/srd/mslist.htm), and a compound was identified if the match was $>80 \%$ (most matches were considerably higher).

Biomass oxidation product quantification. The total organic carbon (TOC), inorganic carbon (IC), and total nitrogen (TN) in reaction liquid was analyzed by using TOC/ TN analyzer (Shimazu, Japan). The HAc product was quantified by GC-FID (GC7890A, Agilent, USA) with DB-FFAP fused - silica capillary column. Prior to product quantification, the reaction solution was neutralized with $37 \% \mathrm{HCl}$ solution to $\mathrm{pH}$ value of 6.4. For GC testing, $900 \mu \mathrm{L}$ neutralized reaction liquid was further acidified by mixing with $100 \mu \mathrm{L}$ of formic acid. Agilent $1260 \mathrm{HPLC}$ with $7.7 \mathrm{~mm} \times 300 \mathrm{~mm}$ PL Hi-Plex H column and VWD $(210 \mathrm{~nm})$ detector was used to further quantify organic acid product. The mobile phase was $5 \mathrm{mM} \mathrm{H}_{2} \mathrm{SO}_{4}$ with flow rate of $0.6 \mathrm{~mL} \mathrm{~min}^{-1}$, and the detection temperature was $25^{\circ} \mathrm{C}$.

Yield $(\%)=$ mass of carbon in product/ mass of carbon in (chitin/ shrimp shell) reactant $\times 100 \%$

Solar energy-driven single-compartment AWE cell. A homemade sealed singlecompartment cell was connected to three commercial PV cells in parallel (power of $50 \mathrm{~W}$ each from Zibo Guosheng Solar Power Company) through a slide rheostat (variable resistance in the range of $0-1 \Omega$ ). Two pieces of enlarged $h p-\mathrm{Ni} / \mathrm{NF}$ and $\mathrm{Ni}_{2} \mathrm{P} / \mathrm{NF}$ with surface area of $28 \mathrm{~cm}^{-2}$ were used as anode and cathode respectively. The experiments were conducted on the roof of our laboratory ( $\mathrm{N} 1^{\circ} 20^{\prime} 54.4^{\prime \prime}$; E $103^{\circ} 40^{\prime} 59.3^{\prime \prime}$ ) at $2-5 \mathrm{pm}$ on 14 June 2019 (partially cloudy).

\section{Data availability}

The data that support the findings of this study are available from the corresponding authors on request.

Received: 15 September 2020; Accepted: 25 February 2021; Published online: 31 March 2021

\section{References}

1. Koraki, D. \& Strunz, K. Wind and solar power integration in electricity markets and distribution networks through service-centric virtual power plants. IEEE Trans. Power Syst. 33, 473-485 (2018).

2. Stuart McMenamin, J., Monforte, F. A. \& Sioshansi, F. P. Environmental benefits of electrification and end-use efficiency. Electr. J. 10, 26-33 (1997).

3. Jacobson, M. Z. et al. $100 \%$ Clean and renewable wind, water, and sunlight allsector energy roadmaps for 139 countries of the world. Joule 1, 108-121 (2017).

4. Olcay, H. et al. Techno-economic and environmental evaluation of producing chemicals and drop-in aviation biofuels via aqueous phase processing. Energy Environ. Sci. 11, 2085-2101 (2018).

5. Olivetti, E. A., Ceder, G., Gaustad, G. G. \& Fu, X. Lithium-ion battery supply chain considerations: analysis of potential bottlenecks in critical metals. Joule 1, 229-243 (2017).

6. Ursua, A., Gandia, L. M. \& Sanchis, P. Hydrogen production from water electrolysis: current status and future trends. Proc. IEEE 100, 410-426 (2012).

7. Chu, S. \& Majumdar, A. Opportunities and challenges for a sustainable energy future. Nature 488, 294-303 (2012).

8. Schiebahn, S. et al. Power to gas: technological overview, systems analysis and economic assessment for a case study in Germany. Int. J. Hydrog. Energy 40, 4285-4294 (2015).
9. Vázquez, F. V. et al. Power-to-X technology using renewable electricity and carbon dioxide from ambient air: SOLETAIR proof-of-concept and improved process concept. J. CO2 Util. 28, 235-246 (2018).

10. Santos, D. M. F., Sequeira, C. A. C. \& Figueiredo, J. L. Hydrogen production by alkaline water electrolysis. Quim. Nova 36, 1176-1193 (2013).

11. Carmo, M., Fritz, D. L., Mergel, J. \& Stolten, D. A comprehensive review on PEM water electrolysis. Int. J. Hydrog. Energy 38, 4901-4934 (2013).

12. Brisse, A., Schefold, J. \& Zahid, M. High temperature water electrolysis in solid oxide cells. Int. J. Hydrog. Energy 33, 5375-5382 (2008).

13. Janjua, M. B. I. \& Le Roy, R. L. Electrocatalyst performance in industrial water electrolysers. Int. J. Hydrog. Energy 10, 11-19 (1985).

14. Strunz, S. Speeding up the energy transition. Nat. Sustain 1, 390-391 (2018).

15. Pivovar, B., Rustagi, N. \& Satyapal, S. Hydrogen at scale (H2@Scale): key to a clean, economic, and sustainable energy system. Electrochem. Soc. Interface 27, 47-52 (2018).

16. Schalenbach, M., Kasian, O. \& Mayrhofer, K. J. J. An alkaline water electrolyzer with nickel electrodes enables efficient high current density operation. Int. J. Hydrog. Energy 43, 11932-11938 (2018).

17. Manabe, A. et al. Basic study of alkaline water electrolysis. Electrochim. Acta 100, 249-256 (2013).

18. Verma, S., Lu, S. \& Kenis, P. J. A. Co-electrolysis of CO2 and glycerol as a pathway to carbon chemicals with improved technoeconomics due to low electricity consumption. Nat. Energy 4, 466-474 (2019).

19. Al Busaidi, A. S., Kazem, H. A., Al-Badi, A. H., Farooq \& Khan, M. A review of optimum sizing of hybrid PV-Wind renewable energy systems in oman. Renew. Sust. Energ. Rev. 53, 185-193 (2016).

20. Notton, G. et al. Intermittent and stochastic character of renewable energy sources: consequences, cost of intermittence and benefit of forecasting. Renew. Sust. Energ. Rev. 87, 96-105 (2018).

21. Mergel, J. \& Stolten, D. Challenges in water electrolysis and its development potential as a key technology for renewable energies. Meet. Abstr. MA2012-02, 348 (2012).

22. Janssen, H., Bringmann, J. C., Emonts, B. \& Schroeder, V. Safety-related studies on hydrogen production in high-pressure electrolysers. Int. J. Hydrog. Energy 29, 759-770 (2004).

23. Symes, M. D. \& Cronin, L. Decoupling hydrogen and oxygen evolution during electrolytic water splitting using an electron-coupled-proton buffer. Nat. Chem. 5, 403 (2013).

24. Rausch, B., Symes, M. D., Chisholm, G. \& Cronin, L. Decoupled catalytic hydrogen evolution from a molecular metal oxide redox mediator in water splitting. Science 345, 1326-1330 (2014)

25. Chen, L., Dong, X., Wang, Y. \& Xia, Y. Separating hydrogen and oxygen evolution in alkaline water electrolysis using nickel hydroxide. Nat. Commun. 7, 11741 (2016).

26. Li, W. et al. Electrolyzer design for flexible decoupled water splitting and organic upgrading with electron reservoirs. Chem. 4, 637-649 (2018).

27. Kirkaldy, N., Chisholm, G., Chen, J.-J. \& Cronin, L. A practical, organicmediated, hybrid electrolyser that decouples hydrogen production at high current densities. Chem. Sci. 9, 1621-1626 (2018).

28. Cha, H. G. \& Choi, K.-S. Combined biomass valorization and hydrogen production in a photoelectrochemical cell. Nat. Chem. 7, 328-333 (2015).

29. You, B., Liu, X., Jiang, N. \& Sun, Y. A general strategy for decoupled hydrogen production from water splitting by integrating oxidative biomass valorization. J. Am. Chem. Soc. 138, 13639-13646 (2016).

30. You, B., Liu, X., Liu, X. \& Sun, Y. Efficient H2 evolution coupled with oxidative refining of alcohols via a hierarchically porous nickel bifunctional electrocatalyst. ACS Catal. 7, 4564-4570 (2017).

31. You, B., Jiang, N., Liu, X. \& Sun, Y. Simultaneous H2 generation and biomass upgrading in water by an efficient noble-metal-free bifunctional electrocatalyst. Angew. Chem. Int. Ed. 55, 9913-9917 (2016).

32. Kim S.-K. Chitin, chitosan, oligosaccharides and their derivatives: biological activities and applications. (CRC Press, Boca Raton, 2010).

33. Kerton, F. M., Liu, Y., Omari, K. W. \& Hawboldt, K. Green chemistry and the ocean-based biorefinery. Green. Chem. 15, 860 (2013).

34. Chen, X., Yang, H., Zhong, Z. \& Yan, N. Base-catalysed, one-step mechanochemical conversion of chitin and shrimp shells into low molecular weight chitosan. Green. Chem. 19, 2783-2792 (2017).

35. Margoutidis, G., Parsons, V. H., Bottaro, C. S., Yan, N. \& Kerton, F. M. Mechanochemical amorphization of $\alpha$-chitin and conversion into oligomers of N-Acetyl-d-glucosamine. ACS Sustain Chem. Eng. 6, 1662-1669 (2018).

36. Yoneda, N., Kusano, S., Yasui, M., Pujado, P. \& Wilcher, S. Recent advances in processes and catalysts for the production of acetic acid. Appl. Catal. A-Gen. 221, 253-265 (2001).

37. Gao, X. et al. Transformation of chitin and waste shrimp shells into acetic acid and pyrrole. ACS Sustain. Chem. Eng. 4, 3912-3920 (2016).

38. Jardine, A. \& Sayed, S. Challenges in the valorisation of chitinous biomass within the biorefinery concept. Curr. Opin. Green Sustain Chem. 2, 34-39 (2016). 
39. Lin, C. S. K. et al. Food waste as a valuable resource for the production of chemicals, materials and fuels. Curr. Situat. Glob. Perspect. Energy Environ. Sci. 6, 426-464 (2013).

40. Goldsmith, Z. K. et al. Characterization of NiFe oxyhydroxide electrocatalysts by integrated electronic structure calculations and spectroelectrochemistry. Proc. Natl Acad. Sci. USA. 114, 3050 (2017).

41. Isogai, A. \& Atalla, R. H. Dissolution of cellulose in aqueous $\mathrm{NaOH}$ solutions. Cellulose 5, 309-319 (1998).

42. Vinu, R. \& Broadbelt, L. J. A mechanistic model of fast pyrolysis of glucosebased carbohydrates to predict bio-oil composition. Energy Environ. Sci. 5, 9808-9826 (2012).

43. Degenstein, J. C. et al. Fast pyrolysis of 13C-labeled cellobioses: gaining insights into the mechanisms of fast pyrolysis of carbohydrates. J. Org. Chem. 80, 1909-1914 (2015).

44. Agarwal, V., Dauenhauer, P. J., Huber, G. W. \& Auerbach, S. M. Ab initio dynamics of cellulose pyrolysis: nascent decomposition pathways at 327 and 600 degrees C. J. Am. Chem. Soc. 134, 14958-14972 (2012).

45. Roy Ghatak, H. Electrolysis of black liquor for hydrogen production: Some initial findings. Int. J. Hydrog. Energy 31, 934-938 (2006).

46. Ghatak, H. R., Kumar, S. \& Kundu, P. P. Electrode processes in black liquor electrolysis and their significance for hydrogen production. Int. J. Hydrog. Energy 33, 2904-2911 (2008).

47. Isogai, T., Saito, T. \& Isogai, A. TEMPO electromediated oxidation of some polysaccharides including regenerated cellulose fiber. Biomacromolecules 11, 1593-1599 (2010).

48. Sugano, Y., Vestergaard, M. D., Yoshikawa, H., Saito, M. \& Tamiya, E. Direct electrochemical oxidation of cellulose: a cellulose-based fuel cell system. Electroanalysis 22, 1688-1694 (2010).

49. Wang, Z.-X., Li, G., Yang, F., Chen, Y.-L. \& Gao, P. Electro-Fenton degradation of cellulose using graphite/PTFE electrodes modified by 2 ethylanthraquinone. Carbohydr. Polym. 86, 1807-1813 (2011).

50. Sugano, Y., Latonen, R.-M., Akieh-Pirkanniemi, M., Bobacka, J. \& Ivaska, A. Electrocatalytic oxidation of cellulose at a gold electrode. ChemSusChem. 7, 2240-2247 (2014).

51. Yang, F., Zhang, Q., Fan, H.-X., Li, Y. \& Li, G. Electrochemical control of the conversion of cellulose oligosaccharides into glucose. J. Ind. Eng. Chem. 20, 3487-3492 (2014).

52. Movil, O., Garlock, M. \& Staser, J. A. Non-precious metal nanoparticle electrocatalysts for electrochemical modification of lignin for low-energy and cost-effective production of hydrogen. Int. J. Hydrog. Energy 40, 4519-4530 (2015).

53. Sugano, Y., Saloranta, T., Bobacka, J. \& Ivaska, A. Electro-catalytic oxidation of hemicelluloses at the Au electrode. Phys. Chem. Chem. Phys. 17, 11609-11614 (2015).

54. Sugano, Y. et al. Specific electrocatalytic oxidation of cellulose at carbon electrodes modified by gold nanoparticles. ChemCatChem 8, 2401-2405 (2016).

55. Xiao, H., Wu, M. \& Zhao, G. Electrocatalytic oxidation of cellulose to gluconate on carbon aerogel supported gold nanoparticles anode in alkaline medium. Catalysts 6, 5 (2016).

56. Hibino, T., Kobayashi, K., Lv, P., Nagao, M. \& Teranishi, S. High performance anode for direct cellulosic biomass fuel cells operating at intermediate temperatures. Bull. Chem. Soc. Jpn. 90, 1017-1026 (2017).

57. Hibino, T., Kobayashi, K., Nagao, M. \& Teranishi, S. Hydrogen production by direct lignin electrolysis at intermediate temperatures. ChemElectroChem 4, 3032-3036 (2017).

58. Hibino, T. et al. Efficient hydrogen production by direct electrolysis of waste biomass at intermediate temperatures. ACS Sustain. Chem. Eng. 6, 9360-9368 (2018).

59. Hibino, T. et al. Direct electrolysis of waste newspaper for sustainable hydrogen production: an oxygen-functionalized porous carbon anode. Appl. Catal. B-Environ. 231, 191-199 (2018).

60. Ju, H., Giddey, S. \& Badwal, S. P. S. Role of iron species as mediator in a PEM based carbon-water co-electrolysis for cost-effective hydrogen production. Int. J. Hydrog. Energy 43, 9144-9152 (2018).

61. Li, S. \& Song, X. Study on the preparation and production factors of a direct lignocellulose biomass fuel cell. J. Electroanal. Chem. 810, 55-61 (2018).

62. Caravaca, A., Garcia-Lorefice, W. E., Gil, S., de Lucas-Consuegra, A. \& Vernoux, $\mathrm{P}$. Towards a sustainable technology for $\mathrm{H} 2$ production: direct lignin electrolysis in a continuous-flow Polymer Electrolyte Membrane reactor Electrochem. Commun. 100, 43-47 (2019).

63. Rafiee, M., Alherech, M., Karlen, S. D. \& Stahl, S. S. Electrochemical aminoxylmediated oxidation of primary alcohols in lignin to carboxylic acids: polymer modification and depolymerization. J. Am. Chem. Soc. 141, 15266-15276 (2019).

64. Holade, Y. et al. Recent advances in the electrooxidation of biomass-based organic molecules for energy, chemicals and hydrogen production. Catal. Sci. Technol. 10, 3071-3112 (2020).

65. You, B., Jiang, N., Sheng, M., Bhushan, M. W. \& Sun, Y. Hierarchically porous urchin-like Ni2P superstructures supported on nickel foam as efficient bifunctional electrocatalysts for overall water splitting. ACS Catal. 6, 714-721 (2016).

66. Ripatti, D. S., Veltman, T. R. \& Kanan, M. W. Carbon monoxide gas diffusion electrolysis that produces concentrated $\mathrm{C} 2$ products with high single-pass conversion. Joule 3, 240-256 (2019).

\section{Acknowledgements}

This work was supported by Nanyang Technological University under NAP award (M408050000), Singapore Ministry of Education Tier 1 program (2018-T1-001-051), and A*STAR Science \& Engineering Research Council AME IRG funding (A1983c0029). The authors acknowledge the Facility for Analysis, Characterization, Testing and Simulation (FACTS), Nanyang Technological University Singapore for use of electron microscopy and X-ray facilities and Campus for Research Excellence and Technological Enterprise (CREATE) for ball mill usage.

\section{Author contributions}

H.Z., H.L., Y.Z., and B.Y. designed the experiments. H.Z. performed electrode fabrication and electrochemical characterizations. D.L., H.Z., D.W., and W.T. conducted the product identification and quantification. J.W., H.Z. and S.W.K. carried out material characterizations. H.Z. and H.L. wrote the manuscript. H.Z., D.L., J.W., P.G., Z.J.X., S.D., Y.Z., B.Y., and H.L. discussed the results and commented on the manuscript.

\section{Competing interests}

H.Z. and H.L. are inventors on a patent application related to this work, filed by Nanyang Technological University Singapore (application no. 10201900445W). The authors declare no other competing interests.

\section{Additional information}

Supplementary information The online version contains supplementary material available at https://doi.org/10.1038/s41467-021-22250-9.

Correspondence and requests for materials should be addressed to Y.Z., B.Y. or H.L.

Peer review information Nature Communications thanks Uwe Schröder and the other, anonymous, reviewer for their contribution to the peer review of this work.

Reprints and permission information is available at http://www.nature.com/reprints

Publisher's note Springer Nature remains neutral with regard to jurisdictional claims in published maps and institutional affiliations.

Open Access This article is licensed under a Creative Commons Attribution 4.0 International License, which permits use, sharing, adaptation, distribution and reproduction in any medium or format, as long as you give appropriate credit to the original author(s) and the source, provide a link to the Creative Commons license, and indicate if changes were made. The images or other third party material in this article are included in the article's Creative Commons license, unless indicated otherwise in a credit line to the material. If material is not included in the article's Creative Commons license and your intended use is not permitted by statutory regulation or exceeds the permitted use, you will need to obtain permission directly from the copyright holder. To view a copy of this license, visit http://creativecommons.org/ licenses/by/4.0/.

(C) The Author(s) 2021 